\title{
A pilot- cross sectional study of palatal Rugae shape and direction among Egyptians and Malaysians
}

\author{
Asmaa Fady Sherif, Ahmed Abdrauof Hashim ${ }^{\dagger}$, Magdy Ashmawy Al Hanafy ${ }^{\dagger}$ and Eman Mostafa Soliman ${ }^{\dagger}$
}

\begin{abstract}
Background: To evaluate the role of different morphological palatal rugae patterns (palatal print) as a tool for personal identification.

Method: A pilot cross-sectional study was carried out on 60 Egyptian subjects and 60 Malaysian subjects. All were above 6 years old, nonsmokers and were sharing the same dietary habits. Palatal impressions were taken from the subjects and a rugogram was issued. Many parameters were included in the rugogram. Rugae shape, direction and unification pattern were the main parameters involved. Modified Trobo classification and Thomas \& Kotz classification were used.

Results: The present study revealed that lines, sinouses and curve shaped rugae were the most frequent rugae patterns among both Egyptians and Malaysians. Forward directed and divergent rugae were more frequent than backwardly directed and convergent rugae among both groups. No significant differences regarding rugae shape, direction and unification status among both sexes in each group were observed. Curve shaped rugae, sinous shaped rugae and complexly shaped rugae were significantly higher in the Malaysian males compared to Egyptian males. Malaysian females had a significant greater number of sinuous shaped rugae than the Egyptian females while the Egyptian females had a greater number of line-shaped rugae than the Malaysian females.
\end{abstract}

Conclusions: This present pilot study revealed that Egyptians and Malaysians shared specific characteristic rugae patterns and direction. Sexual dimorphism was not evident among both populations regarding rugae shape, direction and unification status.

Keywords: Palatal, Rugae, Egyptians, Malaysians, Direction, Unification, Dimorphism

\section{Background}

Identification is considered an exhausting and difficult mission in cases of disfigurement which often happens to drowned bodies, fire victims, and road traffic accidents. Forensic odontology is a golden method that is used in the identification of unknown persons in mass disasters such as earthquakes and tsunamis (Kavitha et al., 2009).

The rugae are defined as the mucosal ridges which are positioned in between the median palatal raphe and the maxillary teeth arch. The palatal rugae appear toward the 3rd month of intrauterine life (Buchtova et al., 2003).

\footnotetext{
*Correspondence: dr_asmaafady@yahoo.com

${ }^{\dagger}$ Equal contributors

Forensic Medicine and Clinical Toxicology Department, Faculty of medicine, Tanta University, Tanta, Egypt
}

During gestation, rugae are prominent and occupy most of the area of the palatal shelves (Ahmed and Hamid, 2015).

Palatal rugae have many functions. Apart from the protection of the bony layer of the hard palate, they have a major role in food transport through the mouth. They prevent dripping of food from the mouth and participate in the chewing food bolus. The palatal rugae are involved in the swallowing process. The contact between food and the taste receptors present at the dorsum of the tongue is improved by these rugae which contribute to the perception of taste, the texture of food qualities and tongue position (Buchtova et al., 2003).

Rugae accommodate various types of intraepithelial sensory structures such as Merckel cells and free nerve endings. Their function is mainly sensory as the tongue 
presses the food against the hard palate during mastication (Pantalacci et al., 2008).

The palatal rugae maintain their shape throughout life, once they are formed during 12th -14th week of prenatal life, their pattern remains unchanged (Paliwal et al., 2010). Although the growth process continues and the palatal measurements (length) may be changed, these rugae stay in the same position throughout the life of a person. Disease, trauma or chemical attack seem able to change the shape of the palatal rugae in rare occasions (Almeida et al., 1995). However, palatal rugae patterns have the ability to overcome decomposition for up to 7 days postmortem (Caldas et al., 2007).

The anatomical position of the rugae inside the oral cavity within the blanket of cheeks keeps them protected from trauma and burns (Bansode and Kulkarni, 2009). Presence of ante-mortem data is another important criteria which differentiate palatal prints from other methods of identification. Ante-mortem data present in dental clinics such as medical records and old prosthetic maxillary impressions or even previous photos are used to compare with post-mortem data. For all these reasons, palatal print can be used as reliable and trusted tool in the field of forensic identification (Ahmed and Hamid, 2015).

Palatoscopy (palatal rugoscopy) means palatal rugae pattern study aiming to ascertain specific person's identity. Many classifications have been established to understand the palatal print and help its implication at forensic practices (Sekhon et al., 2014).

Goria (1911) classification is the oldest one. The rugae are classified according to two parameters, the total rugae number and the area of rugae extension relative to the teeth (Sivaraj, 2013).

Lo'pez de Le'on (1924) system has proposed that a relationship between the personality and palatal rugae pattern exists. Four types of rugae have been suggested and have been labeled as $\mathrm{B}$ for bilious personality, $\mathrm{N}$ belongs to nervous personality, $\mathrm{S}$ is used for sanguinary personality and finally, L refers to lymphatic personality (Mahajan et al., 2014).

Trobo classification (1932) is built on the shape of rugae as the main parameter. This classification divides rugae into two groups: (Simple and composed). Simple rugae are classified into $\mathrm{ABCDEF}$ where (A: point, $\mathrm{B}$ : line, C: curve, D: angle, E: sinuous and F: circle) and Complex rugae are those not fitted to any of the simple ones, instead they are formed by the union of two or more simple rugae and $\mathrm{X}$ type stands for complex rugae (Mahajan et al., 2014).

Many Classifications have been elaborated such as $\mathrm{Da}$ Silva classification (1938) where palatal rugae are classified into two types. A simple type has numbers from one to six and composed type. Composed rugae are those formed by the combination of more than one simple rugae (Caldas et al., 2007). Martins dos Santos (1946) elaborate another classification depends on the morphology and position of each palatine rugae. The rugogram is formed like a fractional equation. The right side is the numerator and the left side is the denominator (Mahajan et al., 2014 \& Popa et al., 2013).

In Lysell classification (1955), rugae are considered as primary (5 $\mathrm{mm}$ or more), secondary (3-5 $\mathrm{mm}$.), and fragmentary (2-3 mm.) Three categories of unification (divergent, convergent and perpendicular rugae) are recognized in this system (Rajan et al., 2013).

A reliable applicable classification is Thomas and Kotze (1983) where the rugae length, shape, direction and unification status are considered. Primary, secondary and fragmentary rugae are involved. Furthermore, the rugae are described based on their shape as curved, wavy, straight and circular rugae. Curved rugae are those crescentic in shape and have gentle curves. Wavy rugae are those having slight curves at the origin or termination of curved rugae. Straight rugae are those running straight without curves from the origin to the end. The last type is the circular rugae that form a complete continuous ring (Bharath et al., 2011).

The direction of the rugae is also considered at Thomas and Kotze classification. It is estimated by measuring the angle formed by two lines. The first is the line joining ruga origin and insertion and the second is a line drawn a perpendicular to the median palatal raphe. Positive angles constitute forwardly directed rugae while negative angles are associated with rugae that are backward. Perpendicular rugae refer to those associated with zero angles. Divergent and convergent rugae are also discussed (Caldas et al., 2007).

Photos taking or oral impressions are routinely used in the field of identification. They provide a detailed and accurate data. Furthermore, they can be preserved. Palatal rugoscopy and the maxillary cast are used to perform comparative analysis (Utsuno et al., 2005).

Direct intraoral inspection is the easiest and the cheapest way to record the palatal rugae pattern. The main limiting factor or disadvantage is difficulty if a future comparative examination is required (Caldas et al., 2007).

Stereoscopy is a technique which produces a threedimensional image of palatal rugae morphology. The principle is the comparison of two pictures taken with the same device but in different angles (Mahajan et al., 2014).

Sterophotogrammetry is another technique where a special apparatus named Traster Marker is used. This technique yields an accurate determination of the length and position of every single palatal ruga (Krishnappa et al., 2013). Overall, the most simple, cheap and reliable method is the comparison of maxillary dental casts (Caldas et al., 2007).

Studies concerning gender and racial differences between Middle East populations and other populations 
are very limited and this current pilot study aimed to evaluate the role of different morphological palatal rugae patterns (palatal print) in the identification of human individuals.

\section{Methodology}

This pilot-cross-sectional study is aimed to evaluate the role of different morphological palatal rugae patterns (palatal print) in the field of personal identification. The aim of conducting pilot studies is to examine the feasibility of an approach that is intended to be used in a larger scale study and it could be applied to all types of research studies (Donker et al., 2013). The research was conducted at the period from July 2013 to July 2015. The study was carried out after approval of the medical research ethics committee of Faculty of Medicine, Tanta University, Egypt. All Individuals were above the age of 6 years. Exclusion criteria were applied, and those not passing it were excluded from the study. The exclusion criteria included patients with palatal neoplasia, those exhibiting severe palatal congenital malocclusion disorders or asymmetries, patients exhibiting severe palatal burns (corrosive ingestions) and patients with a history of previous palatal fractures.

All volunteers were above 6 years old, nonsmokers and sharing the same dietary habits (vegetarian and those eating excessive spicy food were excluded). They were classified into two groups. Each group contains 60 volunteers. Group, I involved 60 Egyptian subjects. All Egyptians were purely Muslims and residents of Gharbia Governate. Group, II accommodated 60 Malaysian subjects. All were Malayan Muslims and living at Gharbia Governate.

Sex and race were distributed equally among the two groups. After obtaining written informed consent from the subjects or their guardians (those below the age of 21 years), the method was explained to the volunteers and any unexpected risks that might appear during the course of the research had been mentioned to both participants and the ethical committee. Each person was given a code to ensure the confidentiality of the data. This labeling or coding system was just to secure the data and hence fair statistical analysis.

The palatal impressions were made according to Verma et al., (2014), where flavored alginate powder was used (Cavex CA37 normal set/ dust free manufactured by Cavex Holland BV P.O. Box 8522003 RW Haarlem the Netherlands). A measured volume of the powder approximately $7 \mathrm{~g}$. was added to approximately $15 \mathrm{ml}$. of plain water and mixed for $30 \mathrm{~s}$ to form an alginate paste. The paste was mixed in a sterilized rubber bowl by using a stainless steel spatula to avoid calculus formation. The volunteer was asked to clean his mouth from any food debris and take a deep breath and relax. Sterile disposable partially perforated trays of the upper jaw of different sizes were used to accommodate the suitable amount of the paste. The tray was inserted in the mouth and it was firmly pressed against the volunteer palate for $90 \mathrm{~s}$ till complete transformation into semisolid, then gently removed.

Within $1 \mathrm{~h}$, dental plaster mix was made at room temperature by adding the measured volume of distilled water to the stone powder (100 g powder with $26 \mathrm{ml}$ water). The mixture was manually mixed for $90 \mathrm{~s}$ by a hand spatula. The mixture was poured over the alginate paste in one direction and it was gently shaken to avoid air bubbles formation. Typically, the setting of the plaster started around $7 \mathrm{~min}$ after pouring the mixture and completed after $30 \mathrm{~min}$, then the cast was separated gently from the tray. The stone powder used in this study was HTM Dent dental stone type 3 manufactured in Egypt LOT: 687,568. The pencil was then used to highlight the rugae. Strong light source and magnifying lens were used to examine the patterns.

A record sheet was designed to accommodate the different parameters used in the current study. The maximum longitudinal diameter of all palatal rugae was measured from the point of its origin till the termination using the Vernier caliper $(0.02 \mathrm{~mm}$.). The size of the rugae was recorded according to Thomas and Kotze classification. Rugae less than $3 \mathrm{~mm}$ (fragmentary rugae) were ignored, those between 3 and $5 \mathrm{~mm}$ were considered secondary rugae, and those more than $5 \mathrm{~mm}$ were considered primary rugae (Bharath et al., 2011). Palatine rugae were classified according to their shape into simple and composed following Trobo classification (Mahajan et al., 2014). Simple rugae were classified into BCDEF, (Type $\mathrm{B}$ for line shaped rugae and those rugae were straight, Type $C$ for curve shaped rugae that show only one curve in their course, Type D for angle shaped rugae wherever an angle was formed, Type E for sinuous shaped rugae that showed more than one curve, Type $\mathrm{F}$ for circle shaped rugae where a definite complete ring was formed). Composed rugae were labeled as X and it involved any shape not classified with the previous simple types. Figure 1 illustrated the morphology of different palatal rugae patterns.

The direction of each primary or secondary rugae was studied and the predominant direction at the impression was recorded. The direction was estimated by measuring the angle formed by the line joining rugae origin and termination with the line drawn a perpendicular to the median raphe. The direction was classified into forwardly directed rugae that were associated with positive angles and backwardly directed rugae that were associated with negative angles (Goyal and Goyal, 2013).

Concerning unification status, divergence was considered if two rugae shared the same origin from the midline but bifurcated further on while convergence was considered if 

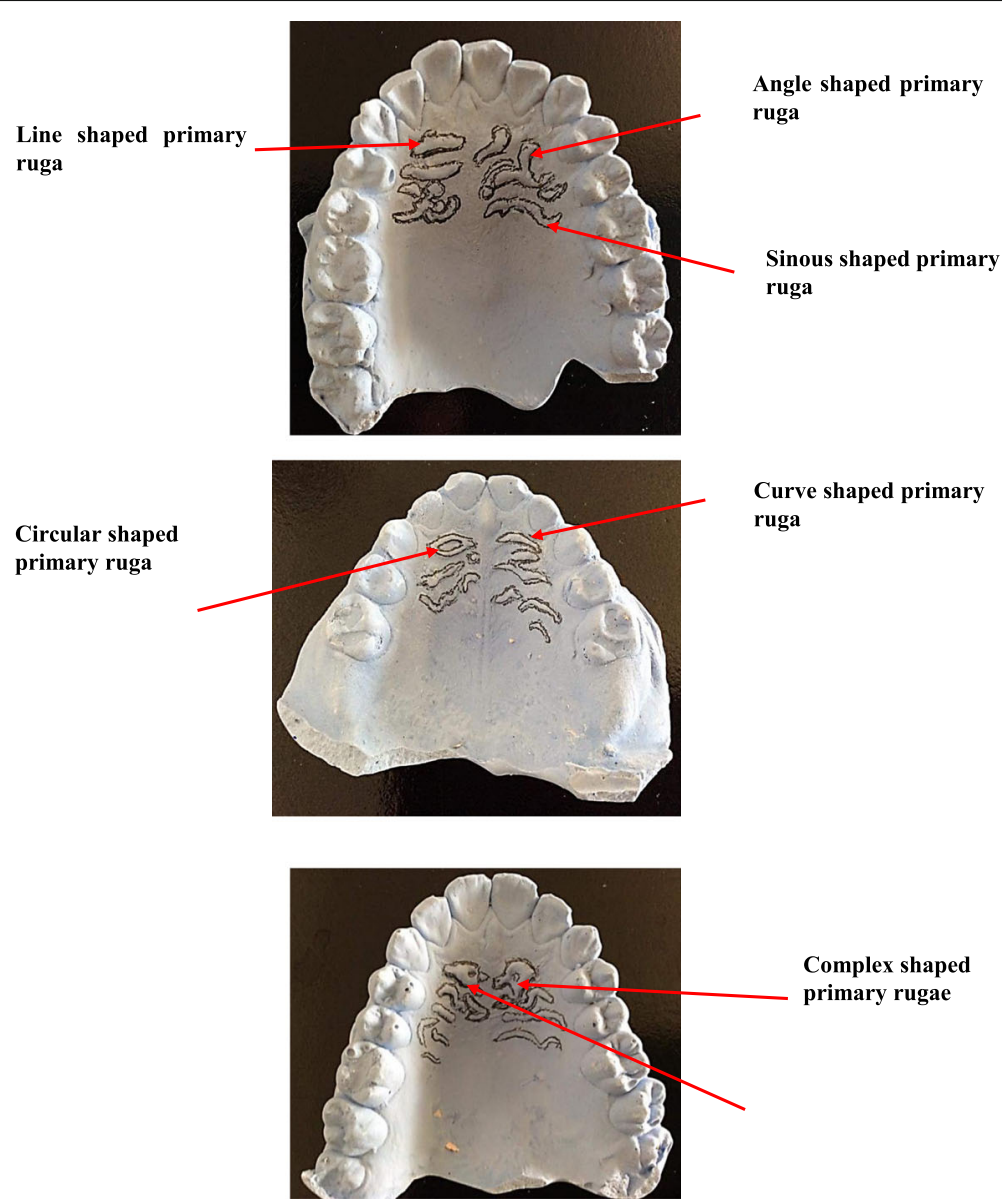

Fig. 1 Palatal impressions photographs showing different rugae patterns. (Line, Angled, Sinous, Circular, Curved \& Complex rugae)

two rugae had separate origins from midline but joined on their lateral portions (Bharath et al., 2011).

All palatal impressions were inspected by two examiners separately and the palatal prints (rugograms) were recorded in separate envelopes and labeled (first record and second record). Then these records were examined by a third examiner who excluded all impressions that had a mismatch between the two records. Overall, 3 impressions only showed such inter-examiner error where 2 secondary line and curve shaped rugae appeared similar.

Associations between rugae shape, direction, unification status and gender or race were tested using chi-square analysis, independent samples T-test and Mann-Whitney U test using the SPSS 20.0 statistical package.

\section{Results}

The present study revealed that, among Egyptians, line shaped rugae were the most frequent followed by curve shaped rugae and sinous shaped rugae respectively. In Malaysians, these three types were the most frequent rugae patterns. Curve shaped rugae were the most common followed by sinous shaped rugae and lastly, line shaped rugae.

The median values for line shaped rugae, curve shaped rugae, and sinous shaped rugae were 5, 2, 2 and 6, 3, 3 rugae in the Egyptian males and Egyptian females respectively for the three rugae types. Concerning Malaysians, the median values for line shaped, curve shaped and sinous shaped rugae were 4, 4, 3 and 3, 4, 3 in the males and females respectively.

Concerning Egyptians, lines constituted the most frequent pattern among both sexes. Lines constituted $(45.03 \%)$ of total rugae among males. Curve shaped rugae (23.93\%) and sinous shaped rugae (21.07\%) constituted the second and third frequent types respectively among Egyptian males. This observation was true regarding the females as lines (43.68\%), curves (22.53\%) and sinous shaped rugae (21.98\%) were the most frequent rugae pattern. Circularly shaped rugae were the least frequent pattern among Egyptian males (0.85\%) and females (1.92\%) as illustrated in Table 1.

As demonstrated in Table 1, line shaped rugae were the most frequent (31.47\%) in Malaysians males, followed by 
Table 1 Comparison of rugae shape among both sexes of Egyptian and Malaysian groups

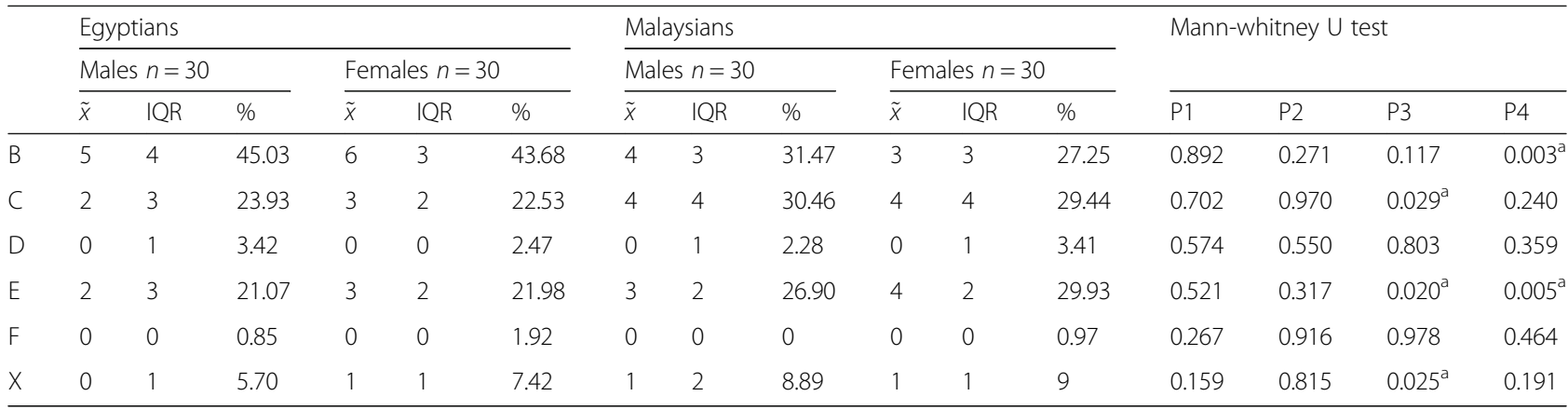

${ }^{\mathrm{a}}$ Significance at $P<0.05$

$\tilde{\mathrm{x}}$ : median

$I Q R$ interquartile range

$B$ : line shaped rugae C: curve shaped rugae, D: angle shaped rugae, E: sinous shaped rugae, F: circle shaped rugae, $X$ : complex shaped rugae

$\mathrm{P} 1=p$ value of Egyptian males versus females

$\mathrm{P} 2=p$ value of Malaysian males versus females

$\mathrm{P} 3=p$ value of Egyptian males versus Malaysian males

$\mathrm{P} 4=p$ value of Egyptian females versus Malaysian females

curve shaped rugae (30.46\%) and sinous shaped rugae (26.90\%). Malaysian females possessed the same three patterns but in different orders. These patterns were sinous shaped (29.93\%), curve shaped (29.44\%) and line shaped rugae $(27.25 \%)$ arranged from the highest to the lowest. The median value of line shaped rugae respecting line shaped rugae was 4 in the males and 3 rugae in the females. Complex shaped rugae were similarly distributed among males and females as there were $(8.89 \%)$ in the males and (9\%) in females. The median values were the same in both rugae types.

To detect the impact of race upon the rugae patterns, males of both studied groups were compared with each other and females also were compared with each other. Curve shaped rugae, sinous shaped rugae and complex shaped rugae were significantly higher $(P$-value $>0.05)$ in the Malaysian males than the Egyptian males (Table 1). Circular shaped rugae were non significantly different among males of both races $(P$ value $<0.05)$ and they were the rarest pattern among the Egyptian males (0.85\%) and were absent among the Malaysian males.

This study found that Malaysian females had significantly greater number of sinuous shaped rugae than the Egyptian females $(P$-value $=0.005)$ while the Egyptian females had significantly greater percentage of line shaped rugae $(43.68 \%)$ than the Malaysian females $(27.25 \%)$ and the $P$-value $=0.003$ as showed in Table 1 .

Regarding curve shaped rugae, they ranked as the second most frequent pattern after the line shaped rugae among Egyptians (22.53\%) and after sinous shaped pattern among Malaysians (29.44\%). Curve shaped rugae showed higher median value among Malaysian females (4 rugae) if compared with the Egyptian females (3 rugae) but this difference still non-significant (Table 1). Circularly shaped rugae were the least frequent pattern among Egyptian and Malaysian males and females with no significant differences between both populations.

Regarding rugae direction, forwardly directed were more common than backwardly directed and convergent rugae

Table 2 Comparison of the predominant rugae direction among both sexes of Egyptians and Malaysians

\begin{tabular}{|c|c|c|c|c|c|c|c|c|c|c|c|c|c|c|c|c|c|c|}
\hline & \multicolumn{5}{|c|}{ Egyptians } & \multicolumn{5}{|c|}{ Malaysians } & \multicolumn{8}{|c|}{ Chi-Square } \\
\hline & \multicolumn{2}{|c|}{ Males } & \multicolumn{2}{|c|}{ Females } & \multirow{2}{*}{$\begin{array}{l}\text { total } \\
\%\end{array}$} & \multicolumn{2}{|c|}{ Males } & \multicolumn{2}{|c|}{ females } & \multirow{2}{*}{$\begin{array}{l}\text { total } \\
\%\end{array}$} & & & & & & & & \\
\hline & $\bar{N}$ & $\%$ & $\bar{N}$ & $\%$ & & $\bar{N}$ & $\%$ & $\bar{N}$ & $\%$ & & $\overline{x^{2}}$ & p1 & $x^{2}$ & p2 & $x^{2}$ & p3 & $x^{2}$ & p4 \\
\hline $\mathrm{fd}$ & 27 & 90 & 23 & 76.7 & 83.30 & 20 & 66.70 & 24 & 80 & 73.3 & 1.920 & 0.166 & 1.364 & 0.234 & 4.812 & $0.028^{a}$ & 0.098 & 0.754 \\
\hline bd & 3 & 10 & 7 & 23.3 & 16.70 & 10 & 33.30 & 6 & 20 & 26.7 & & & & & & & & \\
\hline$\Sigma$ & 30 & 100 & 30 & 100 & 100 & 30 & 100 & 30 & 100 & 100 & & & & & & & & \\
\hline
\end{tabular}

${ }^{\mathrm{a}}$ Significance at $\mathrm{P}<0.05$

$\Sigma$ : total

$N$ number

fd: forwardly directed rugae

bd: backwardly directed rugae

$\mathrm{p} 1: \mathrm{p}$ value of Egyptian males versus females

$p 2: p$ value of Malaysian males versus females

p3: $p$ value of Egyptian males versus Malaysian males

p4: $p$ value of Egyptian females versus Malaysian females 
Table 3 Comparison of rugae unification status among both sexes of Egyptians and Malaysians

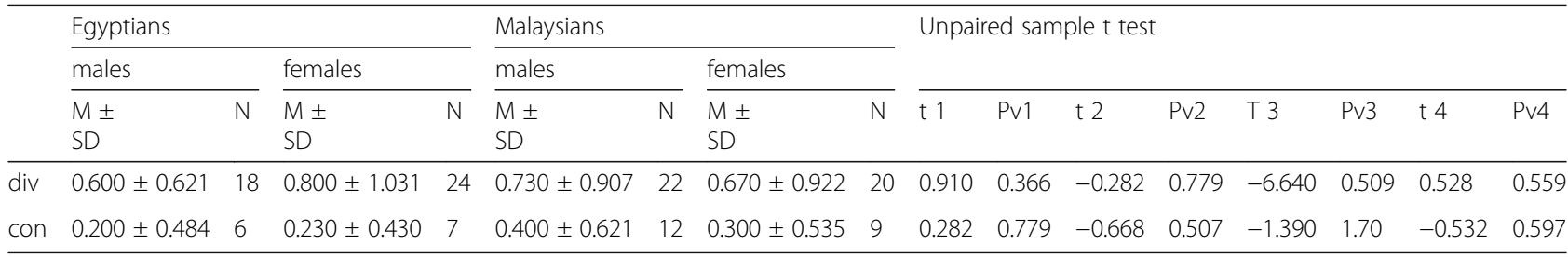

$\mathrm{M} \pm \mathrm{SD}:$ mean \pm standard deviation

$N$ number

Pv1: $p$ value of Egyptian males versus females

Pv2: $p$ value of Malaysian males versus females

Pv3: $p$ value of Egyptian males versus Malaysian males

Pv4: $p$ value of Egyptian females versus Malaysian females

Div: divergent rugae

Con: convergent rugae

among both groups. Egyptians, (83.30\%) showed a predominance of forwardly directed rugae compared with $16.70 \%$ showed backwardly directed rugae as the predominant rugae direction (Table 2). This observation was true in the Malaysians $(73.30 \%$ forwardly directed versus $26.70 \%$ backwardly directed rugae). The gender differences in both groups were not significant. Although significant differences $(P$-value $=0.028) \quad$ were observed between Egyptian and Malaysian males. The females of both groups didn't show such significant differences.

Respecting rugae unification status, divergent rugae were more frequent than convergent rugae in both genders and populations (24 divergent rugae versus 7 convergent rugae in Egyptian females and 22 divergent rugae versus 12 convergent rugae in Malaysian males). However, Table 3 showed the non-significant differences between the Egyptian and Malaysian males and females regarding the predominant rugae unification status.

\section{Discussion}

Non-significant differences in the rugae shape between the two genders in the two studied groups were observed. These findings are partially in agreement with Azab et al., (2015) who found, in a study based on Egyptian sample, that the most frequent shape was the wavy shape (sinous shaped rugae in the current study), followed by the straight (line shaped rugae in the current study) and finally curved and circular shape rugae. The median values for the line, curve, and sinous shaped rugae were 1, 2, 3 rugae for Egyptian males and 2, 2, 3 rugae for Egyptian females.

The results of this study are inconsistent with Fahmi et al., (2001) who observed that Saudi males had significantly higher circular shaped rugae then Saudi females while other patterns were non-significantly different. Furthermore, ELamin et al., (2015) reported that Sudanese females possessed significantly greater sinous shaped rugae than the males.
Additionally, Gondivkar et al., (2011) showed that females had significantly greater sinuous shaped rugae than males among Indian populations. Furthermore, Saraf et al., (2011) demonstrated that circular type of rugae was significantly greater in males among Indian populations.

The conflict between the present study and some literature regarding the rugae shapes may be attributed to the racial differences or to the negligence of the rugae less than $5 \mathrm{~mm}$. (secondary rugae) in some previous research but this study involved these small rugae. Secondary rugae $(3-5 \mathrm{~mm}$.) were as important as the primary ones in estimating different rugae shapes and counts. In this current study, all fragmentary rugae were considered as point shaped and were excluded from rugae shape analysis as they may be confused with artifacts.

Thomas and Kotze (1983) mentioned that although primary rugae had been more extensively studied than secondary and fragmentary rugae, the discrimination between humans was more dependent on the secondary and fragmentary rugae. Moreover, Kolude et al., (2016) revealed that secondary rugae were considered as superior to primary rugae in the field of identification.

Respecting the Egyptians in this present study, line shaped rugae were the most frequent rugae shape (76.67\%), followed by curve shaped rugae $(16.67 \%)$ and lastly sinous shaped rugae (6.66\%). In the Malaysians, Curves (36.67\%), sinouses (33.33\%) and lines (30\%) were the most frequent rugae shapes respectively. Circularly shaped rugae were the least frequent rugae pattern among both genders and both races, furthermore, none of the Malaysian males possessed this pattern of rugae. Significant results were observed among males and females. Malaysian males showed significantly greater curve shaped rugae, sinous shaped rugae and complexly shaped rugae than Egyptian males. Concerning the females, the Egyptians had significantly greater line shaped rugae while the Malaysians had significantly greater sinous shape rugae than the Egyptians. 
The results of this current study partially agree with Abdellatif et al. (2011) who observed that both sexes of Egyptian and Saudi volunteers had insignificant differences regarding rugae shape. Surprisingly, they noted that Egyptians had significantly higher curve shaped rugae than Saudis who showed significantly higher sinous shaped rugae. The differences may be attributed to the different rugae patterns classifications used in each study. They consider cross linked, convergent and divergent rugae as separate rugae patterns which were not the same condition in this study. However and consisting with the current study, the curve, line and sinous shape rugae remained the most frequent rugae types while circularly shaped rugae were the least frequent shape among both Egyptians and Saudis.

This study coincides with Indian results as Shetty et al. (2005) observed that Indian males showed more curved rugae than Tibetan males while Tibetan females showed significantly greater sinous shaped rugae than Indian females. Also among Indians, Nayak et al., (2007) selected their volunteers from two geographically different regions (Southern and Western populations). Wavy, curved and straight rugae were the most common rugae shapes respectively among two groups of Indian populations although the relationship between sex and rugogram failed to be established as nonsignificant differences between both males and females regarding rugae shape were observed, they noticed that Southern Indians had significantly greater straight and curve shaped rugae than Western Indians. Variations in the rugae pattern even among the same race populations living in the different areas may be attributed to the fact that the formation of palatal rugae is a process of environmental and genetic backgrounds.

This study partially agrees with Paliwal et al., (2010) who observed that. In Indian populations, the most frequent rugae shapes were lines, curves, and sinouses, however, this study showed these patterns in a different arrangement. Paliwal et al., (2010) reported that wavy pattern (sinous shaped) followed by curved and lastly straight or line shaped rugae were the most frequent rugae patterns among Indian populations. Furthermore, they mentioned that Kerala populations had significantly greater sinous shaped rugae than Madhya Pradesh population who had more line shaped rugae.

The absence of circularly shaped rugae among Malaysian males in the current study coincides with Verma et al., (2014) who reported that circular rugae were absent in one Indian population while they constituted only $0.6 \%$ of the total rugae patterns in the other studied two populations.

Sivaraj (2013) considered the complexly shaped rugae as a strong positive identification tool thought to be more important than other rugae patterns. That was attributed to the fact that these bizarre shapes were almost unique and non-repeatable. This study agrees with this finding as Malaysian males showed significantly greater complex shaped rugae than the Egyptian males.

Regarding rugae direction in the present study, Egyptian males had a higher percentage of forwarding directed rugae (90\%) than females $(76.70 \%)$ while Malaysian females showed a higher percentage of forwarding directed rugae $(80 \%)$ than the Malaysian males (66.70\%). Variations in rugae direction among males and females of the same race were non-significant.

These results coincide with those obtained by Azab et al., (2015) as forwarding directed rugae were more frequent than backward directed rugae in Egyptian males and females. The results of this study are partially in agreement with Ahmed and Hamid (2015) results who observed the predominance of forwarding than backward directed rugae. However, they mentioned that Sudanese males had significantly greater forwarding directed rugae than the Sudanese females.

Gondivkar et al., (2011) \& Jibi et al., (2011) noticed that forwarding directed rugae were more frequent than backward directed rugae and no significant differences were observed between Indian males and females regarding rugae direction.

The results of this study are compatible with results of Goyal and Goyal (2013) who found that forwardly directed rugae $(48.3 \%$ in the males and $40.8 \%$ in the females) were more common than backwardly directed rugae $(17.8 \%$ in the males and $19.6 \%$ in the females) among Rwandan populations. Additionally, nonsignificant differences between both sexes were noticed.

Regarding rugae direction, it was observed that forwarding directed rugae (83.30\%) were more frequent than the backward directed ones (16.70\%) among Egyptians. Forward directed rugae $(73.30 \%)$ were more frequent than backward directed rugae (26.70\%) among Malaysians as well. The Egyptian male showed significantly different distribution when compared with the Malaysian males. On the other hand, no significant differences were observed when the Egyptian females and Malaysian females were compared with each other.

The results of this study are partially in agreement with Reddy et al., (2014) who reported that forwardly directed rugae were more common among South Indians (90\%) and North Indians $(70 \%)$ than backwardly directed rugae $(10 \%$ and 30\%) for South and North Indians respectively while Chinese showed equal distribution of both types of rugae. In all conditions, these variations were not significant.

The significant racial differences among Egyptian and Malaysian males as regards to rugae direction in this study are different from Jibi et al., (2011) who reported non-significant differences between Muslims and Hindus regarding rugae direction.

Regarding the unification status in this study, divergent rugae were more frequent than convergent rugae. 
The divergent rugae were more frequent than convergent rugae among males and females in both Egyptian and Malaysian group with no significant differences.

The results of this study partially agree with the results obtained by Azab et al., (2015). The mean value of Egyptian males in the current study was $0.600 \pm 0.621$ divergent rugae which was the same $(0.67 \pm 0.78)$ as Azab et al., (2015) while the mean value of male was $0.200 \pm 0.484$ convergent rugae which was far from that $(1.48 \pm 1.42$ convergent rugae) of Azab et al., (2015) as they noticed that convergent rugae were more frequent (mean value: $1.49 \pm 1.56$ rugae) than divergent rugae (mean value: 0.63 \pm 0.77 rugae) among Egyptians. In all conditions, both studies observed that these variations were not significant. Moreover, Ibeachu et al., (2015) denied the impact of sex in unification status as they reported non-significant differences among Nigerian males and females.

The previous results of this study are inconsistent with Fahmi et al., (2001) who conducted their study among Saudis and found significant differences between different sexes. The mean values of convergent rugae were $15.1 \pm 14.4$ and $8.6 \pm 12.4$ in Saudi females and males respectively. Furthermore, ELamin et al., (2015) mentioned that the mean value of Sudanese male was $1.2 \pm 1$ convergent rugae which were significantly greater than the females $(0.9 \pm 1.1)$.

The results of this study regarding unification status are not in line with the Indian results. Saraf et al., (2011) observed that converging rugae were significantly greater in females ( 2 as a median value) than males of the same nationality (zero as a median value). Additionally, Bharath et al., (2011), Jibi et al., (2011) \& Babu et al., (2013) conducted their study in India and concluded that males had significantly more convergent rugae than the females that showed a higher incidence of divergent rugae than the males. Chopra et al., (2013) reported that Indian females exhibited significantly greater divergent rugae count than the Indian males.

In this study, divergent rugae were more common than convergent rugae in both Egyptians and Malaysians. In Egyptian group, 42 divergent rugae were observed compared to 13 convergent rugae. Malaysian group possessed 42 divergent rugae while convergent rugae were 21 rugae. Moreover, this study revealed non-significant variations between both Egyptian and Malaysian races.

These findings are inconsistent with Abdellatif et al., (2011) who reported that diverging rugae were significantly higher in number among Saudi populations while converging rugae were significantly higher among Egyptians. Saudi populations possessed (27) divergent compared to (8) convergent ones while Egyptians had (15) and (23) divergent and convergent rugae respectively.

Results obtained in this study go in the same direction as those obtained by Reddy et al., (2014) who conducted their study among South and North Indians and among Chinese. All the three groups had more divergent rugae than convergent ones. They had 17 divergent rugae $(56.7 \%)$ versus 4 convergent rugae (13.3\%). Nonsignificant differences between both races were observed.

The variation in between this study and previous studies regarding the rugae unification status may be due to racial differences or due to different classifications used in each research. Most of the previous studies classified rugae patterns into three or four rugae patterns (line, curve, sinous and sometimes circular) and discarded angled shaped rugae from their classifications. They considered the convergent and divergent rugae as additional patterns (Chopra et al., 2013). Further studies with greater numbers of subjects are required to verify the findings in this study.

\section{Conclusion}

In this pilot study, the rugae shape, direction, and unification status are not significantly different among males and females in Egypt and Malaysia. Variation in rugae pattern and direction among Egyptians and Malaysians were observed. It is advisable to use secondary rugae and they should be considered as important as the primary rugae regarding rugae shape, direction and unification status.

\section{Abbreviations \\ B: Line shaped rugae; bd: Backwardly directed rugae; C: Curve shaped rugae; D: Angle shaped rugae; E: Sinous shaped rugae; F: Circle shaped rugae; $X$ : Complex shaped rugae; Con: Convergent rugae; Div: Divergent rugae.; $\mathrm{fd}$ : Forwardly directed rugae; IQR: Interquartile range; $\mathrm{M} \pm \mathrm{SD}$ : Mean \pm standard deviation; N: Number; $\mathrm{p}$ : $p$ value of Egyptian males versus females; p2: $p$ value of Malaysian males versus females; $33: p$ value of Egyptian males versus Malaysian males; 4 : $p$ value of Egyptian females versus Malaysian females; Pv1: $p$ value of Egyptian males versus females; Pv2: p value of Malaysian males versus females; Pv3: $p$ value of Egyptian males versus Malaysian males; Pv4: $p$ value of Egyptian females versus Malaysian females; SPSS: Statistical Package of Social Sciences; $\tilde{x}$ : Median; $\Sigma$ : Total}

\section{Funding}

This study was funded by the authors.

\section{Availability of data and materials}

"The dataset supporting the conclusions of this article is included within the article and its additional file".

\section{Authors' contributions}

Dr. AFSh corresponding author, collected the cases, made the palatal impressions, analyze the data and wrote the drafts of this study. Prof. AH: choose the methodology and revised the written research. Prof. MA: choose the methodology and revised the written research. Prof. ES: cases selection, palatal print (rugogram) examination and recording, data analysis editing and revising written research. All authors read and approved the final manuscript.

\section{Ethics approval and consent to participate}

The study was carried out after approval of the medical research ethical committee of Faculty of Medicine, Tanta University. All Individuals were above the age of 6 years. After obtaining written Informed consent from the subjects or their guardians (Those below age of 21 years), the whole maneuver had been explained to the volunteers and any unexpected risks 
that may appear during the course of the research had been declared to participants and the ethical committee on time.

\section{Consent for publication}

Not applicable.

\section{Competing interests}

No financial or non-financial conflict of interests.

\section{Publisher's Note}

Springer Nature remains neutral with regard to jurisdictional claims in published maps and institutional affiliations.

Received: 12 September 2017 Accepted: 1 February 2018

Published online: 08 February 2018

\section{References}

Abdellatif AM, Awad SM, Hammad SM (2011) Comparative study of palatal rugae shape in two samples of Egyptian and Saudi children. Pediatr Dent J 21(2): $123-128$

Ahmed AA, Hamid A (2015) Morphological study of palatal rugae in a Sudanese population. Int J Dent 2015:1-8

Almeida MA, Phillips C, Kula K, Tulloch C (1995) Stability of the palatal rugae as landmarks for analysis of dental casts. Angle Orthod 65(1):43-48

Azab SM, Magdy R, El Deen MAS (2015) Patterns of palatal rugae among adult Egyptian population. Egyptian J Forensic Sci 6:78-83

Babu GS, Bharath TS, Kumar NG (2013) Characteristics of palatal Rugae patterns in west Godavari population of India. J Clin Diagn Res 7(10):2356

Bansode SC, Kulkarni MM (2009) Importance of palatal rugae in individual identification. J Forensic Dent Sci 1(2):77

Bharath ST, Kumar GR, Dhanapal R, Saraswathi TR (2011) Sex determination by discriminant function analysis of palatal rugae from a population of coastal Andhra. J Forensic Dent Sci 3(2):58-60

Buchtova M, Tichy F, Putnova I, Misek I (2003) The development of palatal rugae in the European pine vole, Microtus subterraneous (Arvicolidae, Rodentia). Folia Zool 52(2):127-136

Caldas IM, Magalhaes T, Afonso A (2007) Establishing identity using cheiloscopy and palatoscopy. Forensic Sci Int 165(1):1-9

Chopra A, Rao NC, Gupta N, Vashisth S (2013) Palatal rugae and arch length: a tool in gender determination. Universal Res J Dent 3(2):54

Donker T, Petrie K, Proudfoot J, Clarke J, Birch MR, Christensen H (2013) Smartphones for smarter delivery of mental health programs: a systematic review. J Med Internet Res 15(11), e247. https://doi.org/10.2196/jmir.2791

ELamin El, Reddy NR, Ali EO (2015) Palatal rugae: systematic analysis of its shape and dimensions in Sudanese population. Int J Dent Clin 7(1):15

Fahmi FM, Al-Shamrani SM, Talic YF (2001) Rugae pattern in a Saudi population sample of males and females. Saudi Dent J 13(2):92-95

Gondivkar SM, Patel S, Gadbail AR, Gaikwad RN, Chole R, Parikh RV (2011) Morphological study of the palatal rugae in western Indian population. J Forensic Legal Med 18(7):310-312

Goyal S, Goyal S (2013) Study of palatal rugae pattern of Rwandan patients attending the dental Department at King Faisal Hospital, Rwanda: a preliminary study. Rwandan Med J 70(1):19-25

Ibeachu PC, Didia BC, Fawehinmi HB (2015) Determination of sexual dimorphism by Odontometric study using Discriminant function analysis of adult Ikwerre. Dental Cast Popul 6:7

Jibi PM, Gautam KK, Basappa N, Raju OS (2011) Morphological pattern of palatal rugae in children of Davangere. J Forensic Sci 56(5):1192-1197

Kavitha B, Einstein A, Sivapathasundharam B, Saraswathi TR (2009) Limitations in forensic odontology. J Forensic Dent Sci 1(1):8

Kolude B, Akinyele A, Joshua OT, Ahmed L (2016) Ethnic and gender comparison of rugae patterns among clinical dental trainees in Ibadan, Nigeria. Pan Afr Med J 23:204

Krishnappa S, Srinath S, Bhardwaj P (2013) Palatal rugoscopy: implementation in forensic odontology-a review. J Adv Med Dent Sci 1(2):53-59

Mahajan R, Dar MA, Risam SS (2014) Paltoscopy/ rugoscopy: a potential tool in human identification. J Evol Med Dent Sci 40(3):10081

Nayak P, Acharya AB, Padmini AT, Kaveri H (2007) Differences in the palatal rugae shape in two populations of India. Arch Oral Biol 52(10):977-982

Paliwal A, Wanjari S, Parwani R (2010) Palatal rugoscopy: establishing identity. J Forensic Dent Sci 2(1):27-31
Pantalacci S, Prochazka J, Martin A, Rothova M, Lambert A, Bernard L, Laudet V (2008) Patterning of palatal rugae through sequential addition reveals an anterior/posterior boundary in palatal development. BMC Dev Biol 8(1):116

Popa MF, Ştefănescu C, Corici PD (2013) Forensic identification elements with the help of rugoscopy in children. Romanian J Leg Med 21(2):95-100

Rajan VP, John JB, Stalin A, Priya G, Abuthagir AKS (2013) Morphology of palatal rugae patterns among 5-15 years old children. J Pharm Bio Allied Sci 5(1):43S-47S

Reddy SVM, Gautam NS, Rao TH, Gautam NR, Koganti R, Agarwal R (2014) Comparison of palatal Rugae pattern among north Indian, south Indian and Chinese students of Manipal University. Adv Hum Biol 4(2):40-44

Saraf A, Bedia S, Indurkar A, Degwekar S, Bhowate R (2011) Rugae patterns as an adjunct to sex differentiation in forensic identification. J Forensic Odontostomatol 29(1):14-19

Sekhon HK, Sircar K, Singh S, Jawa D, Sharma P (2014) Determination of the biometric characteristics of palatine rugae patterns in Uttar Pradesh population: a cross-sectional study. Indian J Dent Res 25(3):331-335

Shetty SK, Kalia S, Patil K, Mahima VG (2005) Palatal rugae pattern in Mysorean and Tibetan populations. Indian J Dent Res 16(2):51-55

Sivaraj A (2013) Significance of palatal rugae in orthodontics. J Orofac Res 3(3):202-209

Thomas CJ, Kotze TJ (1983) The palatal rugae pattern: a new classification. J Dent Assoc S Afr 38(3):153-157 Quoted from Bharath ST, Kumar GR, Dhanapal R, Saraswathi TR (2011) Sex determination by discriminant function analysis of palatal rugae from a population of coastal Andhra. Journal of Forensic Dental Sciences, 3(2):58-60

Utsuno H, Kanoh T, Tadokoro O, Inoue K (2005) Preliminary study of post mortem identification using lip prints. Forensic Sci Int 149(2):129-132

Verma KG, Verma P, Bansal N, Basavaraju S, Sachdeva SK, Khosa R (2014) Correlation of palatal rugoscopy with gender, palatal vault height and $A B O$ blood groups in three different Indian populations. Ann Med Health Sci Res 4(5):769-774

\section{Submit your manuscript to a SpringerOpen ${ }^{\circ}$ journal and benefit from:}

- Convenient online submission

- Rigorous peer review

- Open access: articles freely available online

- High visibility within the field

Retaining the copyright to your article

Submit your next manuscript at $>$ springeropen.com 